\title{
The Application of Zonisamide to Patients Suffering from Dementia with Lewy Bodies: Emerging Clinical Data
}

\author{
Babak Tousi ${ }^{1,2}$ \\ James B Leverenz ${ }^{2}$ \\ 'Cleveland Clinic Lerner College of \\ Medicine of Case Western Reserve \\ University, Cleveland, OH, USA; ${ }^{2}$ Lou \\ Ruvo Center for Brain Health, Cleveland \\ Clinic, Cleveland, $\mathrm{OH}$, USA
}

\begin{abstract}
Zonisamide is an anti-epileptic medication with multiple mechanisms of action and a favorable safety profile. Zonisamide may interact with Lewy body dementia pathophysiology through a mechanism unrelated to its original indication. Zonisamide has shown efficacy as adjunct therapy for the management of motor symptoms in patients with Parkinson's disease (PD). Given that dementia with Lewy bodies (DLB) and PD are considered subtypes of a Lewy body disease spectrum, zonisamide was investigated for the treatment of parkinsonism in DLB. Phase II and phase III clinical trials were conducted in patients with DLB in Japan. In both studies, participants were randomized to receive 12 weeks of zonisamide 25 or $50 \mathrm{mg}$ /day or placebo. Zonisamide significantly improved the Unified Parkinson's Disease Rating Scale Part III (UPDRS-III) without affecting the MiniMental State Examination (MMSE) or Neuropsychiatry Inventory-10 (NPI-10) scores at week 12. In 2018, zonisamide received Japanese regulatory approval for the additional indication of parkinsonism in DLB. This review discusses the emerging clinical data on zonisamide in the field of DLB.
\end{abstract}

Keywords: dementia with Lewy bodies, zonisamide, clinical trial, parkinsonism

\section{Background}

Current symptomatic management of dementia with Lewy bodies (DLB) in clinical practice remains suboptimal. There are currently no FDA-approved medications for the treatment of DLB in the USA. Therefore, clinicians prescribe off-label medications which are approved for Alzheimer's disease, Parkinson's disease (PD), or other neurobehavioral diseases to ameliorate the symptoms of DLB. ${ }^{1,2}$

Donepezil has been on the market for Alzheimer's dementia for a long time and received Japanese regulatory approval for the management of cognitive changes in patients with DLB in 2014. Management of parkinsonian symptoms, a core feature of DLB, is widely based on levodopa therapy. The use of other anti-parkinsonian agents is limited because of their possible adverse effects on cognition and behavior. Parkinsonism in DLB can be partially responsive to levodopa but there remains an increased risk of worsening psychiatric symptoms. The response may be mild to moderate in some patients, but the total daily dose given to DLB patients is limited, owing to the risk of exacerbation of visual hallucinations or other behavioral symptoms. ${ }^{3}$

The lack of therapeutics may be partially due to the scarcity of clinical trials on DLB. Aside from donepezil, there had been no successful phase III clinical trials
Correspondence: Babak Tousi

Lou Ruvo Center for Brain Health, U-I0,

Cleveland Clinic, 9500 Euclid Ave,

Cleveland, OH, 44195, USA

Tel +I 2162376400

Email batous@ccf.org 
for DLB until 2018, when zonisamide, a compound initially synthesized as an anti-epileptic agent, was shown to have therapeutic benefit in the management of parkinsonism in patients with DLB. ${ }^{4}$

\section{Zonisamide in Current Clinical Practice}

Zonisamide is a mixed monoamine oxidase B (MAO-B) inhibitor, sodium and calcium channel blocker, glutamate release inhibitor, and carbonic anhydrase inhibitor, with a relatively long elimination half-life of approximately 63 hours in plasma. ${ }^{5}$ It was initially approved as adjunct therapy for partial seizures in adults in 1989 in Japan and 2000 in the USA. ${ }^{5,6}$ The initial dose for treatment of seizures in adults is $100 \mathrm{mg}$ daily, with a gradual increase of $100 \mathrm{mg} /$ day at 2-week intervals to a dose of $400 \mathrm{mg} /$ day. Doses up to $600 \mathrm{mg} /$ day have been used, but there is no suggestion of increased efficacy in doses above $400 \mathrm{mg} /$ day. $^{5}$

In Japan, 1008 patients participated in phase II and phase III trials of zonisamide for seizure. ${ }^{7}$ Adverse effects were observed in $52 \%$ of patients. Major adverse effects were drowsiness $(24 \%)$, ataxia $(13 \%)$, loss of appetite $(11 \%)$, gastrointestinal symptoms $(7 \%)$, decrease in spontaneity $(6 \%)$, and mental slowing $(5 \%){ }^{7}$ In a metaanalysis of six clinical trials, including patients between 12 and 80 years of age, there were no statistically significant adverse effects associated with zonisamide. ${ }^{8}$ Most of the adverse events related to withdrawal from the study were dizziness, difficulty concentrating, and somnolence. ${ }^{8}$ Zonisamide is licensed in the USA for adjunct therapy of partial seizures in adults. In Japan and Europe, its use has expanded to both monotherapy and adjunct therapy for focal and generalized seizures. ${ }^{7,8}$ Owing to its multiple mechanisms of action, the therapeutic use of zonisamide for a variety of neurological disorders, including PD, ${ }^{9}$ migraine, ${ }^{10,11}$ anxiety, ${ }^{12}$ essential tremor, ${ }^{13}$ and other neurological conditions, has been investigated over the past few years, with mixed results.

\section{Zonisamide in Animal Models of Parkinsonism}

In an early study, when zonisamide was coadministered with levodopa to a nigrotomized rat, a significant increase in contralateral rotational behavior (referring to behavior exhibited by a turned rat in order to return to the upright position) was noted within 20 minutes of injection. ${ }^{14}$
Zonisamide significantly suppressed chemically induced tremors in rats. The researchers reported similar experiences when dopaminergic transmission was blocked by pretreatment with haloperidol or monoamines were depleted by pretreatment with reserpine. ${ }^{15}$ Neither of these pretreatments changed the outcome of the experiment and zonisamide maintained the anti-tremor benefit, suggesting a non-dopaminergic mechanism of action. ${ }^{15}$

In a study of hemiparkinsonian rat models, zonisamide was coadministered with levodopa (a dopamine precursor) or apomorphine (a dopamine agonist) or by itself. Zonisamide given intravenously enhanced the benefit of levodopa therapy on motor symptoms, but not when coadministered with apomorphine or by itself. The authors concluded that the anti-parkinsonian benefit of zonisamide is due to dopaminergic modification in the striatum rather than non-dopaminergic pathways. ${ }^{16}$

Zonisamide was shown to increase the levels of dopamine and homovanillic acid in the striatum intracellularly and extracellularly in rats, and had no effect on dopamine reuptake. ${ }^{17}$ Different anti-parkinsonian mechanisms of action for zonisamide have been hypothesized: as reversible inhibition of MAO- $\mathrm{B}^{18}$ and enhancing delta receptorassociated neurotransmitter release. ${ }^{19}$ Zonisamide has been proposed to have neuroprotective potential against oxidative stress and dopaminergic neurodegeneration in animal models, and different hypotheses have been proposed. ${ }^{20-22}$

\section{Zonisamide in Human Clinical Trials of Parkinson's Disease}

In 2001, a Japanese group reported improvements in wearing-off episodes and other parkinsonian symptoms in seven out of nine patients when zonisamide was given as an adjunct to levodopa therapy. ${ }^{23}$ Their open-label study was designed after an observation of zonisamide given to a PD patient with seizures, which improved not only the seizures, but also his parkinsonian symptoms. A doubleblind study of low-dose zonisamide $(25,50,100 \mathrm{mg})$ as an adjunct with levodopa in PD patients reported similar improvement in their primary outcome of Unified Parkinson's Disease Rating Scale Part III (UPDRS-III) without worsening dyskinesias. ${ }^{9}$ Adverse effects were similar between the low-dose $(25 \mathrm{mg}$ and $50 \mathrm{mg}$ ) and placebo groups, while there was a higher incidence of side effects in the $100 \mathrm{mg}$ group, especially somnolence and apathy. Since then, a few clinical trials have assessed 
Table I Characteristics of Published Double-Blind, Randomized Placebo-Controlled Trials of Zonisamide for Treatment of Motor Function in PD and DLB

\begin{tabular}{|c|c|c|c|c|c|c|c|c|}
\hline Study & $\begin{array}{l}\text { Trial } \\
\text { Information }\end{array}$ & Patients & $\mathbf{n}$ & Duration & $\begin{array}{l}\text { Zonisamide } \\
\text { Dose }\end{array}$ & Primary Endpoint & $\begin{array}{l}\text { Other } \\
\text { Outcome } \\
\text { Scales }\end{array}$ & Results \\
\hline $\begin{array}{l}\text { Murata } \\
(2007)^{9}\end{array}$ & Phase IIb/III & PD & 347 & 12 weeks & $\begin{array}{l}25 \mathrm{mg}, 50 \mathrm{mg}, \\
100 \mathrm{mg}\end{array}$ & $\begin{array}{l}\text { Change from baseline } \\
\text { in the total score on } \\
\text { the UPDRS-III }\end{array}$ & $\begin{array}{l}\text { UPDRS-I, } \\
\text { UPDRS-II, } \\
\text { UPDRS-IV, } \\
\text { H\&Y score }\end{array}$ & $\begin{array}{l}\text { "Off" time significantly } \\
\text { reduced in } 50 \mathrm{mg} \text { and } \\
100 \mathrm{mg} \text { groups. } \\
\text { No difference in } \\
\text { dyskinesia. } \\
\text { Reduction in UPDRS-III } \\
\text { score in all arms, but only } \\
\text { significant for } 25 \text { and } \\
50 \mathrm{mg} \text { groups }\end{array}$ \\
\hline $\begin{array}{l}\text { Murata } \\
(2015)^{37}\end{array}$ & Phase Ilb/III & PD & 389 & 12 weeks & $25 \mathrm{mg}, 50 \mathrm{mg}$ & $\begin{array}{l}\text { Change from baseline } \\
\text { in daily "off" time by } \\
\text { patient's diaries }\end{array}$ & $\begin{array}{l}\text { UPDRS-I, } \\
\text { UPDRS-II, } \\
\text { UPDRS-III, } \\
\text { UPDRS-IV, } \\
\text { PDQ-39 }\end{array}$ & $\begin{array}{l}\text { "Off" time reduced. } \\
\text { Somnolence was higher } \\
\text { for zonisamide } 25 \text { and } \\
50 \mathrm{mg} \text { groups. } \\
\text { No significant difference in } \\
\text { UPDRS }\end{array}$ \\
\hline $\begin{array}{l}\text { Murata } \\
(2016)^{38}\end{array}$ & $\begin{array}{l}\text { Phase III } \\
\text { JapicCTI- } \\
101198\end{array}$ & PD & 196 & 12 weeks & $25 \mathrm{mg}, 50 \mathrm{mg}$ & $\begin{array}{l}\text { Change from baseline } \\
\text { in the UPDRS-III total } \\
\text { score at the final } \\
\text { assessment }\end{array}$ & $\begin{array}{l}\text { UPDRS-I, } \\
\text { UPDRS-II, } \\
\text { UPDRS-IV }\end{array}$ & $\begin{array}{l}\text { Improvement in UPDRS-III } \\
\text { in } 25 \mathrm{mg} \text { and } 50 \mathrm{mg} \\
\text { groups. } \\
\text { No significant difference in } \\
\text { adverse effect. } \\
\text { "Off" time reduced } \\
\text { significantly only in } 25 \mathrm{mg} \\
\text { group }\end{array}$ \\
\hline $\begin{array}{l}\text { Murata } \\
(2018)^{28}\end{array}$ & $\begin{array}{l}\text { Phase II } \\
\text { JapicCTI- } \\
\text { I } 22040\end{array}$ & DLB & 137 & 12 weeks & $25 \mathrm{mg}, 50 \mathrm{mg}$ & $\begin{array}{l}\text { Change from baseline } \\
\text { in the UPDRS-III total } \\
\text { score at the final } \\
\text { assessment }\end{array}$ & $\begin{array}{l}\text { MMSE, } \\
\text { NPI- I0, ZBI }\end{array}$ & $\begin{array}{l}\text { Significant improvement in } \\
\text { UPDRS-III score in } 50 \mathrm{mg} \\
\text { group. } \\
\text { AEs were higher in the } \\
\text { zonisamide } 50 \mathrm{mg} \text { than the } \\
25 \mathrm{mg} \text { and placebo groups }\end{array}$ \\
\hline $\begin{array}{l}\text { Murata } \\
(2020)^{4}\end{array}$ & $\begin{array}{l}\text { Phase III } \\
\text { JapicCTI- } \\
\text { I52839 }\end{array}$ & DLB & 346 & 12 weeks & $25 \mathrm{mg}, 50 \mathrm{mg}$ & $\begin{array}{l}\text { Change from baseline } \\
\text { in the UPDRS-III total } \\
\text { score at the final } \\
\text { assessment }\end{array}$ & $\begin{array}{l}\text { MMSE, } \\
\text { NPI-I0 }\end{array}$ & $\begin{array}{l}\text { Significant improvement in } \\
\text { UPDRS-III score in } 25 \mathrm{mg} \\
\text { and } 50 \mathrm{mg} \text { groups. } \\
\text { No difference in } \\
\text { AEs except decreased } \\
\text { appetite in } 50 \mathrm{mg} \text { group }\end{array}$ \\
\hline
\end{tabular}

Abbreviations: PD, Parkinson's disease; DLB, dementia with Lewy bodies; UPDRS, Unified Parkinson's Disease Rating Scale; MMSE, Mini-Mental State Examination; $\mathrm{n}$, number of participants; ZBI, Zarit Burden Interview; NPI, Neuropsychiatric Inventory; AE, adverse event.

the efficacy of zonisamide ${ }^{24}$ as an adjunct treatment for PD (Table 1). A meta-analysis of four combination therapies with zonisamide treatment for PD patients revealed decreases in UPDRS-III scores and wearing-off time in the zonisamide group compared to placebo. ${ }^{24}$

In 2009, zonisamide was approved in Japan as adjunct therapy with levodopa for the treatment of $\mathrm{PD} .^{25}$
The Movement Disorder Society Evidence-Based Medicine Committee has included zonisamide as a clinically useful and efficacious treatment for adjunct therapy in early/stable PD and motor fluctuations. ${ }^{26}$ The committee concluded that there was insufficient evidence to support the use of zonisamide for the treatment of dyskinesia. 


\section{Zonisamide in Human Clinical Trials of DLB}

Given that DLB and PD are considered subtypes of the Lewy body disease spectrum, zonisamide was investigated for the treatment of parkinsonism in DLB. A case series reported that zonisamide improved parkinsonism without worsening cognition in patients with DLB. ${ }^{27}$

\section{Randomized Placebo-Controlled Phase II Study}

In 2018, the results of a randomized phase II clinical trial of zonisamide as an adjunct to levodopa therapy for parkinsonism in DLB were published ${ }^{28}$ (Table 1). In that study, 158 patients in an early stage of DLB received zonisamide as adjunct therapy in three arms of $25 \mathrm{mg}$, $50 \mathrm{mg}$, and placebo in a 12 -week phase II trial. ${ }^{28}$ Major inclusion criteria were the presence of parkinsonism (UPDRS-III score $\geq 10$ ) and a Mini-Mental State Examination (MMSE) total score of 10-26. ${ }^{29,30}$

There was a significant improvement in UPDRS-III total score at week 12 in the zonisamide $50 \mathrm{mg}$ group compared with placebo. The UPDRS-III score was also significantly lower by week 8 . There was no significant difference between zonisamide $25 \mathrm{mg}$ and placebo. The total score for secondary outcomes of MMSE, ${ }^{30} \mathrm{NPI}-10,{ }^{31}$ and the Zarit Burden Interview (ZBI), ${ }^{32}$ which measures the perceived burden of caregiving, did not change significantly from baseline in any group. Weight loss, diminished appetite, and rash were reported more frequently in the zonisamide than the placebo group. The overall adverse events rate was comparable between zonisamide $25 \mathrm{mg}$ and placebo, but higher for zonisamide $50 \mathrm{mg} .{ }^{28}$

\section{Randomized Placebo-Controlled Phase III Study}

A multicenter phase III trial was conducted in Japan between 2015 and 2017 to assess the effect of zonisamide on parkinsonism in patients with DLB who were on a stable dose of levodopa therapy. The participants received zonisamide ( 25 or $50 \mathrm{mg} /$ day) or placebo for 12 weeks followed by a 40 -week open-label extension. ${ }^{4}$ Both treatment arms met the primary outcome of improvement in UPDRS-III score ${ }^{29}$ at week 12 compared to placebo. Among the items on UPDRS-III, resting tremor was the only item which showed significant improvement compared to placebo in both 25 and $50 \mathrm{mg}$ groups.
The major secondary outcomes were UPDRS-III score at weeks 4 and 8 , the change from baseline at week 12 in Neuropsychiatry Inventory-10 (NPI-10) ${ }^{31}$ score and $\mathrm{MMSE}^{30}$ total score. There was a non-significant trend for the NPI-10 score $^{31}$ to have decreased in both zonisamide treatment groups compared to placebo.

A decrease in UPDRS-III score was observed in all arms of the study (placebo and zonisamide groups) at week 4. That remained unchanged in the placebo group but continue to decrease for both 25 and $50 \mathrm{mg}$ treatment groups. There was a significant difference in the change in MMSE score in the $50 \mathrm{mg}$ group compared with placebo. The most common adverse events for which a causal relationship with zonisamide could not be ruled out were diminished appetite and somnolence. ${ }^{4}$

All 346 patients who participated in the open-label phase, ${ }^{33}$ after the double-blind phase III study, received $25 \mathrm{mg} /$ day zonisamide over 2 weeks and then flexible dosing ( 25 or $50 \mathrm{mg} /$ day) depending on the patient's condition in a 40-week extension phase. The results of the open-label extension phase were presented in 2019; zonisamide led to a continued reduction in UPDRS-III until 24-28 weeks, which was maintained until the final evaluation visit without any significant decline in cognition (MMSE score change) or behavioral changes (NPI-10). ${ }^{33}$

Weight loss and diminished appetite have been recorded in both pivotal trials of zonisamide in DLB patients. ${ }^{4,28}$ Loss of appetite was more frequent in the $50 \mathrm{mg}$ arm of the study. ${ }^{34}$

The investigators in the phase III trial concluded that it is important to emphasize that dose of $100 \mathrm{mg}$ and above, which are traditionally used for seizures, were not used for DLB patients, as patients with PD who received zonisamide doses of $100 \mathrm{mg} /$ day showed significant worsening of their neurocognitive symptoms in the initial clinical trials.

In the phase III trial of DLB, ${ }^{4}$ the mean MMSE score at week 12 was significantly decreased from baseline in the $50 \mathrm{mg}$ arm of the study. In 2018, zonisamide received Japanese regulatory approval for the additional indication of parkinsonism in DLB. ${ }^{35}$ The decision was based on the phase III trial, which showed that zonisamide $25 \mathrm{mg}$ and $50 \mathrm{mg}$ improved motor symptoms, with a good safety profile. The new indication was treatment of parkinsonism persisting in patients with DLB using levodopa. ${ }^{35}$

\section{Discussion}

Four clinical trials of PD patients and both phase II and phase III trials of DLB patients, who received zonisamide as 
adjunct therapy to levodopa, reported significant improvement in motor functions (Table 1). The mean doses of levodopa therapy in the two randomized clinical trials on DLB were low, $319 \mathrm{mg}$ /day in the phase II trial and $254 \mathrm{mg} /$ day in the phase III trial. ${ }^{4,28}$ Using the higher dose of levodopa in patients with DLB may increase the risk of visual hallucinations or behavioral symptoms. The benefit of zonisamide on parkinsonism was moderate at best, but was achieved with a relatively low daily dose of levodopa, which could be an alternative to increasing the levodopa dose.

In a previous study, an increase in the dose of levodopa in DLB patients provided motor benefit without exacerbation of psychosis in only $22 \%$ of patients. ${ }^{3}$ Phase II/III trials of zonisamide provided this evidence of improvement in motor symptoms without worsening psychiatric symptoms in $61.5 \%$ and $50.5 \%$ of DLB patients on $25 \mathrm{mg}$ and $50 \mathrm{mg}$ doses, respectively. ${ }^{4}$

A number of questions remain, however, which must be addressed in future clinical trials.

First, the possible adverse effect of zonisamide on cognition in DLB could be underestimated by these phase II/III trials. The average MMSE score at baseline was 21.7 in the phase III trial, ${ }^{4}$ suggesting a milder stage of dementia. It was noted that the MMSE score decreased significantly from baseline in the $50 \mathrm{mg}$ group at week 12, but was not reported in the openlabel extension. The use of the MMSE in isolation helps to assess the severity of dementia but may not be the ideal primary outcome to capture cognitive changes in DLB patients in a trial. The adverse effect of mental slowing, which was reported in patients with epilepsy, may present in DLB patients if they are in more advanced stages or taking medication in higher doses or for a longer time. ${ }^{7}$ There is an age-related decline in cognitive function in the general population. ${ }^{36}$ DLB is predominantly a disease of the elderly, and zonisamide carries certain risks in the elderly which warrant additional caution.

Second, both double-blind studies were conducted over a relatively short period of 12 weeks, so the efficacy and adverse effects of the medication when it is given for a longer duration remain to be seen. The publication of the open-label extension of the phase III trial may add more information.

Third, it remains to be known whether the benefit provided from zonisamide was beyond what could have been achieved by a slight increase in the dose of levodopa. Zonisamide may be considered in DLB subjects who cannot tolerate an increase in the dose of levodopa because of gastrointestinal side effects or the development of hallucinations. The investigators in the two trials reported a low incidence of psychiatric adverse events and no evidence of a dose-dependent effect, but the number of adverse events was slightly higher in the $50 \mathrm{mg}$ group and a $100 \mathrm{mg}$ dose, which has been shown to cause worsening cognition in PD patients, was not used.

Finally, the risk-benefit ratio of zonisamide as adjunct therapy for DLB is not known. The relatively common side effect of loss of appetite may add an unjustified burden for patients and their families. There is no evidence that the slight improvement in UPDRS-III score with zonisamide can be translated into an improvement in the quality of life for patients or even caregivers, as no difference in ZBI score was noted. None of these trials applied functional outcome or quality of life measures.

Zonisamide may be a safe and effective adjunct to levodopa for the management of parkinsonism in DLB. The therapeutic benefit is mild and the maximum dose may be limited owing to the effects on cognition. Further studies should include more sensitive assessment of cognition and the effects on quality of life and functional impact.

\section{Acknowledgment}

This work was supported by the National Institutes of Health/National Institute of Neurological Disorders and Stroke [U01 NS100610].

\section{Disclosure}

Dr Babak Tousi reports being a consultant for Eisai and Biogen, and grants from the Alzheimer's Drug Discovery Foundation, outside the submitted work.

Dr James JB Leverenz reports grants from the NIH, during the conduct of the study; personal fees from Acadia, personal fees from Biogen, personal fees from Eisai, personal fees from Takeda, and grants from GE Healthcare, outside the submitted work. The authors report no other conflicts of interest in this work.

\section{References}

1. McKeith IG, Boeve BF, Dickson DW, et al. Diagnosis and management of dementia with Lewy bodies: fourth consensus report of the DLB Consortium. Neurology. 2017;89(1):88-100. doi:10.1212/ WNL.0000000000004058

2. Tousi B. Diagnosis and management of cognitive and behavioral changes in dementia with Lewy bodies. Curr Treat Options Neurol. 2017;19(11). doi:10.1007/s11940-017-0478-x 
3. Goldman JG, Goetz CG, Brandabur M, Sanfilippo M, Stebbins GT. Effects of dopaminergic medications on psychosis and motor function in dementia with Lewy bodies. Mov Disord. 2008;23 (15):2248-2250. doi:10.1002/mds.22322

4. Murata M, Odawara T, Hasegawa K, et al. Effect of zonisamide on parkinsonism in patients with dementia with Lewy bodies: a Phase 3 randomized clinical trial. Parkinsonism Relat Disord. 2020;76:91-97. doi:10.1016/j.parkreldis.2019.12.005

5. U.S. Food and Drug Administration. Zonisamide approvable labeling [Internet]. Approved labeling text; 2000. Available from: https:// www.accessdata.fda.gov/drugsatfda_docs/label/2000/20789lbl.pdf. Accessed April 20, 2021.

6. Schmidt D, Jacob R, Loiseau P, et al. Zonisamide for add-on treatment of refractory partial epilepsy: a European double-blind trial. Epilepsy Res. 1993;15(1):67-73. doi:10.1016/0920-1211(93)90011-U

7. Seino M. Review of zonisamide development in Japan. Seizure. 2004;13:S2-S4. doi:10.1016/j.seizure.2004.04.015

8. Verrotti A, Loiacono G, Di Sabatino F, Zaccara G. The adverse event profile of zonisamide: a meta-analysis. Acta Neurol Scand. 2013. doi:10.1111/ane.12147

9. Murata M, Hasegawa K, Kanazawa I, et al. Zonisamide improves motor function in Parkinson disease: a Randomized, Double-Blind Study. Neurology. 2007;68(1):45-50. doi:10.1212/01.wnl.00002502 36.75053 .16

10. Ashkenazi A, Benlifer A, Korenblit J, Silberstein SD. Zonisamide for migraine prophylaxis in refractory patients. Cephalalgia. 2006;26 (10):1199-1202. doi:10.1111/j.1468-2982.2006.01191.x

11. Mohammadianinejad SE, Abbasi V, Sajedi SA, et al. Zonisamide versus topiramate in migraine prophylaxis: a double-blind randomized clinical trial. Clin Neuropharmacol. 2011;34(4):174-177. doi:10.1097/WNF.0b013e318225140c

12. Kinrys G, Vasconcelos E Sa D, Nery F. Adjunctive zonisamide for treatment refractory anxiety. Int J Clin Pract. 2007;61(6):1050-1053. doi:10.1111/j.1742-1241.2007.01365.x

13. Zesiewicz TA, Ward CL, Hauser RA, Sanchez-Ramos J, Staffetti JF, Sullivan KL. A double-blind placebo-controlled trial of zonisamide (Zonegran) in the treatment of essential tremor. Mov Disord. 2007.

14. Gluck MR, Santana LA, Granson H, Yahr MD. Novel dopamine releasing response of an anti-convulsant agent with possible antiParkinson's activity. J Neural Transm. 2004;111(6):713-724. doi:10.1007/s00702-004-0107-1

15. Miwa H, Hama K, Kajimoto Y, Kondo T. Effects of zonisamide on experimental tremors in rats. Parkinsonism Relat Disord. 2008;14 (1):33-36. doi:10.1016/j.parkreldis.2007.05.008

16. Nishijima H, Miki Y, Ueno S, Tomiyama M. Zonisamide enhances motor effects of levodopa, not of apomorphine, in a rat model of Parkinson's disease. Parkinsons Dis. 2018;2018:1-7. doi:10.1155/ 2018/8626783

17. Okada M, Kaneko S, Hirano T, et al. Effects of zonisamide on dopaminergic system. Epilepsy Res. 1995;22(3):193-205. doi:10.1016/0920-1211(95)00078-X

18. Sonsalla PK, Wong LY, Winnik B, Buckley B. The antiepileptic drug zonisamide inhibits MAO-B and attenuates MPTP toxicity in mice: clinical relevance. Exp Neurol. 2010;221(2):329-334. doi:10.1016/j. expneurol.2009.11.018

19. Yamamura S, Ohoyama K, Nagase H, Okada M. Zonisamide enhances delta receptor-associated neurotransmitter release in striato-pallidal pathway. Neuropharmacology. 2009;57(3):322-331. doi:10.1016/j.neuropharm.2009.05.005

20. Asanuma M, Miyazaki I, Diaz-Corrales FJ, et al. Neuroprotective effects of zonisamide target astrocyte. Ann Neurol. 2010;67 (2):239-249. doi:10.1002/ana.21885

21. Costa C, Tozzi A, Luchetti E, et al. Electrophysiological actions of zonisamide on striatal neurons: selective neuroprotection against complex I mitochondrial dysfunction. Exp Neurol. 2010;221 (1):217-224. doi:10.1016/j.expneurol.2009.11.002
22. Sano H, Murata M, Nambu A. Zonisamide reduces nigrostriatal dopaminergic neurodegeneration in a mouse genetic model of Parkinson's disease. $J$ Neurochem. 2015;134(2):371-381. doi:10.11 $11 /$ jnc. 13116

23. Murata M, Horiuchi E, Kanazawa I. Zonisamide has beneficial effects on Parkinson's disease patients. Neurosci Res. 2001;41 (4):397-399. doi:10.1016/S0168-0102(01)00298-X

24. Matsunaga S, Kishi T, Iwata N. Combination therapy with zonisamide and antiparkinson drugs for Parkinson's disease: a metaanalysis. J Alzheimers Dis. 2017;56(4):1229-1239. doi:10.3233/ JAD-161068

25. Dainippon Sumitomo Pharma Co. Parkinson's disease drug "TRERIEF" obtained manufacturing and marketing approval [Internet]; 2009. Available from: https://www.ds-pharma.com/ir/ news/2009/20090121.html. Accessed April 20, 2021.

26. Fox SH, Katzenschlager R, Lim SY, et al. International Parkinson and movement disorder society evidence-based medicine review: update on treatments for the motor symptoms of Parkinson's disease. Mov Disorders. 2018;33(8):1248-1266. doi:10.1002/ mds. 27372

27. Odawara T, Shiozaki K, Togo T, Hirayasu Y. Administration of zonisamide in three cases of dementia with Lewy bodies. Psychiatry Clin Neurosci. 2010;64(3):327-329. doi:10.1111/j.14401819.2010.02075.x

28. Murata $\mathrm{M}$, Odawara $\mathrm{T}$, Hasegawa $\mathrm{K}$, et al. Adjunct zonisamide to levodopa for DLB parkinsonism: a Randomized Double-Blind Phase 2 Study. Neurology. 2018;90(8):e664-e672. doi:10.1212/WNL.000 0000000005010

29. Movement Disorder Society Task Force on Rating Scales for Parkinson's Disease. The Unified Parkinson's Disease Rating Scale (UPDRS): status and recommendations. Mov Disord. 2003;18 (7):738-750.

30. Folstein MF, Folstein SE, McHugh PR. "Mini-mental state". A practical method for grading the cognitive state of patients for the clinician. J Psychiatr Res. 1975.

31. Cummings JL, Mega M, Gray K, Rosenberg-Thompson S, Carusi DA, Gornbein J. The neuropsychiatric inventory: comprehensive assessment of psychopathology in dementia. Neurology. 1994;44 (12):2308. doi:10.1212/WNL.44.12.2308

32. Arai Y, Kudo K, Hosokawa T, Washio M, Miura H, Hisamichi S. Reliability and validity of the Japanese version of the Zarit Caregiver burden interview. Psychiatry Clin Neurosci. 1997;51(5):281-287. doi:10.1111/j.1440-1819.1997.tb03199.x

33. Toya S, Murata M, Odawara T, et al. Long-term efficacy for parkinsonism and safety of zonisamide in patients with dementia with Lewy bodies: a phase III trial. Neurology. 2019;92(15Supplement): P4.1-011.

34. Hasegawa K, Kenji K, Maruyama H, Konishi O, Toya S, Odawara T. Efficacy and safety of zonisamide in dementia with Lewy bodies patients with Parkinsonism: a post hoc analysis of two randomized, double-blind, placebo-controlled trials. J Alzheimers Dis. 2020.

35. Sumitomo Dainippon Pharma Co. Sumitomo dainippon pharma obtains approval in Japan for TRERIEF, a therapeutic agent for Parkinson's disease, for an additional indication of Parkinsonism in dementia with Lewy bodies [Internet]; 2018. Available from: https://www.ds-pharma. com/ir/news/2018/20180702.html. Accessed April 20, 2021.

36. Kaur U, Chauhan I, Gambhir IS, Chakrabarti SS. Antiepileptic drug therapy in the elderly: a clinical pharmacological review. Acta Neurol Belg. 2019;119(2):163-173. doi:10.1007/s13760-019-01132-4

37. Murata M, Hasegawa K, Kanazawa I, et al. Zonisamide improves wearing-off in Parkinson's disease: a Randomized, Double-Blind Study. Mov Disord. 2015;30(10):1343-1350. doi:10.1002/mds.26286

38. Murata M, Hasegawa K, Kanazawa I, Shirakura K, Kochi K, Shimazu R. Randomized placebo-controlled trial of zonisamide in patients with Parkinson's disease. Neurol Clin Neurosci. 2016;4 (1):10-15. doi: $10.1111 / \mathrm{ncn} 3.12026$ 


\section{Publish your work in this journal}

Drug Design, Development and Therapy is an international, peerreviewed open-access journal that spans the spectrum of drug design and development through to clinical applications. Clinical outcomes, patient safety, and programs for the development and effective, safe, and sustained use of medicines are a feature of the journal, which has also been accepted for indexing on PubMed Central. The manuscript management system is completely online and includes a very quick and fair peer-review system, which is all easy to use. Visit http://www. dovepress.com/testimonials.php to read real quotes from published authors.

Submit your manuscript here: https://www.dovepress.com/drug-design-development-and-therapy-journal 